\title{
REPRESENTAÇÕES SOCIAIS SOBRE TDAH E MEDICALIZAÇÃO
}

\author{
REPRESENTACIONES SOCIALES SOBRE TDAH Y MEDICALIZACIÓN
}

SOCIAL REPRESENTATIONS ON ADHA AND MEDICALIZATION

\author{
Suzi Maria Nunes CORDEIRO ${ }^{1}$ \\ Solange Franci Raimundo YAEGASHI ${ }^{2}$ \\ Lucilia Vernaschi de OLIVEIRA ${ }^{3}$
}

RESUMO: Este artigo apresenta os resultados de uma pesquisa sobre as representações sociais de 14 professores do Ensino Fundamental I, de 6 escolas públicas de uma cidade do interior do estado do Paraná sobre Transtorno de Déficit de Atenção e Hiperatividade (TDAH) e medicalização. $\mathrm{O}$ estudo justifica-se pela necessidade de compreender como o TDAH é concebido pelos professores, no intuito de contribuir com os profissionais da Educação, de modo a ampliar seus conhecimentos sobre o transtorno em discussão e os estimular à pesquisa. Os resultados revelam que as participantes da pesquisa conceituam o TDAH como um transtorno que afeta a aprendizagem e provoca problemas comportamentais, necessitando de tratamento medicamentoso. Conclui-se que as representações sociais das professoras estão ancoradas em conceitos propagados pela mídia, pelos cursos de formação de professores e pela orientação dada às escolas pelos profissionais da Saúde. Embora manifestem dúvida em relação ao diagnóstico recebido pelos alunos, ainda possuem o consenso de que a medicalização é a melhor forma de tratamento para os alunos com TDAH.

PALAVRAS-CHAVE: TDAH. Dificuldades de aprendizagem. Medicalização. Prática pedagógica.

RESUMEN: Este artículo presenta los resultados de una investigación respecto a las representaciones sociales de 14 profesores de la Enseñanza Primaria I, de 6 escuelas públicas de una ciudad del interior del Estado de Paraná sobre Trastorno de Déficit de Atención e Hiperactividad (TDAH) y medicalización. El estudio se justifica por la necesidad de comprender cómo el TDAH es concebido por los profesores, con el fin de contribuir con los profesionales de la Educación, para ampliar sus conocimientos sobre el trastorno en discusión y estimularlos a la investigación. Los resultados revelan que las participantes de la investigación conceptúan el TDAH como un trastorno que afecta el aprendizaje y provoca problemas de conducta, necesitando tratamiento medicamentoso. Se concluye que las representaciones sociales de las profesoras están basadas en conceptos propagados por los medios, por los cursos de formación

\footnotetext{
${ }^{1}$ Universidade Estadual de Maringá (UEM), Maringá - Paraná - Brasil. Doutoranda em Educação. ORCID: <http://orcid.org/0000-0003-0353-3825>. E-mail: prof-suzi@hotmail.com

${ }^{2}$ Universidade Estadual de Maringá (UEM), Maringá - Paraná - Brasil. Pós-Doutora em Psicologia pela Universidade de São Paulo (USP). Doutora em Educação pela Universidade Estadual de Campinas (UNICAMP). ORCID: <http://orcid.org/0000-0002-7666-7253>. E-mail: solangefry@ gmail.com

${ }^{3}$ Universidade Estadual de Maringá (UEM), Maringá - Paraná - Brasil. Doutoranda em Educação. ORCID: <http://orcid.org/0000-0003-1356-537X>.E-mail: luvernaschi@gmail.com
} 
de profesores y por la orientación realizada en las escuelas por los profesionales de la Salud. Aunque manifiestan duda en relación al diagnóstico recibido por los alumnos, todavía poseen el consenso de que la medicalización es la mejor forma de tratamiento para los alumnos con TDAH.

PALABRAS CLAVE: Dificultades de aprendizaje. Medicamento. Práctica pedagógica.

ABSTRACT: This article has as objective to presents the results about a research around the social representation of 14 acting teachers in 6 Elementary Schools in the state of Paraná regarding to Attention Deficit Hyperactivity Disorder (ADHD) and medication. This study is justified because of the relevance to understand how ADHD is conceived by teachers in order to contribute with their professional education so that to extend their knowledge about this disorder and encourage them to develop research in this segment. The results show that the participants of the research grade the ADHD how a disorder which affects the learning and causes behavioral problems, requiring a drug treatment. In conclusion, the social representations of the teachers are based on concepts propagated by the media, courses teacher training and direction given to school by the health professionals. Even though they manifest doubts with diagnostic received about the students, they have a consensus that the medicalization is the best way to treat the students diagnosed with ADHD.

KEYWORDS: ADHD. Learning disability. Medicalization. Pedagogical practice.

\section{Introdução}

As diversas pesquisas encontradas na literatura científica sobre Transtorno de Déficit de Atenção e Hiperatividade (TDAH) salientam diferentes aspectos, como os métodos de avaliação para o diagnóstico, os possíveis tratamentos e os medicamentos utilizados. Encontramos estudos realizados por especialistas como neurologistas, psicopedagogos, dentre outros, porém, grande parte das pesquisas sobre o TDAH está relacionada ao campo da Saúde (CRUZ; OKAMOTO; FERRAZZA, 2016; CRUZ et al, 2016; LEONARDO; SUZUKI, 2016). O número de pesquisadores do campo da Educação que escrevem sobre o tema ainda é restrito.

Levando em consideração esse contexto, pensamos ser pertinente a pesquisa sobre TDAH partindo de autores do campo da Educação, a fim de atingir o público desta área, sobretudo os que estão atuando diretamente na escola, visando contribuir para uma melhor compreensão do assunto.

Algumas pesquisas, como a de Benczik (2010), com base em estudos internacionais, revelam que apenas 3\% das crianças na faixa etária de 6 a 12 anos possuem de fato o referido transtorno. Todavia, se considerarmos as diferentes regiões do Brasil, os índices de crianças encaminhadas e diagnosticadas com TDAH são alarmantes e muito superiores aos apontados 
pelo estudo da autora supracitada. Essas contradições despertaram inquietações, gerando a necessidade de entendermos os motivos que levam a esse aumento nos diagnósticos, podendo ser os exacerbados encaminhamentos realizados pela escola, com relatórios que induzem médicos a terem um diagnóstico pronto e/ou a má qualidade na avaliação dos clínicos.

Considerando esse contexto, a presente pesquisa proporciona uma reflexão sobre a seguinte problemática norteadora: quais são as representações sociais que os professores do Ensino Fundamental I ( $1^{\circ}$ ao $5^{\circ}$ ano) têm sobre o TDAH e o processo de medicalização? O objetivo geral é caracterizar as representações sociais dos professores do $1^{\circ}$ ao $5^{\circ}$ ano do Ensino Fundamental sobre o Transtorno de Déficit de Atenção e Hiperatividade, bem como sobre o processo de medicalização do mencionado transtorno, visto que o conceito que possuem sobre a temática influencia na prática pedagógica com os alunos com TDAH. Com os objetivos específicos verificamos qual a principal matriz conceitual acerca de TDAH e de medicalização que prevalece no grupo dessas profissionais; por fim, constatamos as práticas pedagógicas realizadas com os alunos com TDAH pelas professoras participantes da pesquisa.

O estudo justifica-se pela necessidade de compreender como o Transtorno de Déficit de Atenção e Hiperatividade é concebido por professores, no intuito de proporcionar uma tomada de consciência sobre os pensamentos e as práticas com alunos com TDAH, além de contribuir com os docentes e demais profissionais da Educação, de modo a ampliar seus conhecimentos sobre o transtorno em discussão e os estimular à pesquisa, com o propósito de que escrevam sobre o tema, desenvolvendo um olhar crítico sobre o que se passa na sala de aula.

Considerando tais pressupostos, a presente pesquisa adota como referencial teóricometodológico a Teoria das Representações Sociais (TRS). Esta investiga como se formam e como funcionam os sistemas de referência que utilizamos para classificar objetos, em nosso caso o TDAH, e para interpretar os acontecimentos da realidade cotidiana (ALVES-MAZZOTTI, 2008). Para Moscovici (2015), as representações sociais não são apenas opiniões sobre um determinado tema, mas teorias coletivas sobre o real, sistemas que possuem lógicas e linguagem particular, envolvendo valores e conceitos, que juntos constroem definições coletivas e são compartilhadas pelos grupos, influenciando, consequentemente, as condutas desejáveis ou admitidas moralmente.

\section{Metodologia}

Participaram desse estudo 14 professoras do Ensino Fundamental I ( $1^{\circ}$ ao $5^{\circ}$ ano), de escolas municipais de uma cidade do interior do estado do Paraná. Seguindo os princípios éticos 
para a realização da pesquisa, solicitamos a anuência da Secretaria Municipal de Educação (SEDUC) da referida cidade e, em seguida, submetemos o trabalho ao Comitê Permanente de Ética em Pesquisa com Seres Humanos (COPEP) da Universidade Estadual de Maringá. Depois de aprovado, realizamos uma visita à SEDUC, a fim de obtermos o levantamento do número de alunos com TDAH. As escolas nas quais desenvolvemos a pesquisa foram selecionadas aleatoriamente, mas tínhamos como critério que tivessem matriculados alunos com diagnóstico de TDAH.

Os dados fornecidos pela SEDUC revelam a existência de 49 escolas de Ensino Fundamental nesse município. Nossa amostra é restrita a 12\% dessas instituições (6 escolas). São escolas com infraestrutura esteticamente adequada, porém, com escassez de espaços para as crianças (bibliotecas pequenas, falta de brinquedotecas e salas multimídias etc.). A maioria está localizada nas regiões periféricas da cidade. Em cada uma das 6 escolas, entrevistamos as professoras que se dispuseram a participar do estudo. Portanto, a participação foi por adesão e de forma voluntária. Para mantermos a identidade das professoras, identificamos cada uma com a letra $\mathrm{P}$ e um número $(\mathrm{P} 1, \mathrm{P} 2, \mathrm{P} 3 \ldots)$.

A presente pesquisa apresenta-se com caráter qualiquantitativo e descritivo. Utilizamos como instrumentos de coleta de dados: um questionário sociodemográfico, a fim de delinearmos o perfil das participantes, cuja análise dos dados foi quantitativa, por meio de tabulação dos dados; e um Teste de Associação Livre de Palavras (TALP), para constatarmos as evocações das professoras sobre TDAH e medicalização, em que a análise foi realizada por meio de categorias de análise, de forma qualitativa.

Foram realizadas observações das turmas das docentes participantes, a fim de colher algumas informações sobre os alunos com diagnóstico de Transtorno de Déficit de Atenção e Hiperatividade (TDAH) e de suas práticas pedagógicas para com os mesmos. Para tanto, utilizamos um Roteiro Semiestruturado de Observação do Cotidiano Escolar. Esse instrumento tem por finalidade observar os comportamentos tanto das crianças com o diagnóstico de TDAH quanto da prática pedagógica de seus professores nas salas de aula.

\section{Resultados e discussões}

No que se refere aos dados do questionário sociodemográfico, das quatorze professoras entrevistadas, treze $(92,9 \%)$ se formaram em Pedagogia e apenas uma $(7,1 \%)$ tinha formação em Letras. Quanto à formação complementar, nove $(64,3 \%)$ entrevistadas fizeram curso de 
Especialização Lato Sensu na área de Educação, uma (7,1\%) fez Mestrado em Educação e quatro $(28,6 \%)$ não fizeram nenhum curso. No que diz respeito ao tempo de atuação, três $(21,4 \%)$ exercem a profissão há menos de 10 anos e onze $(78,6 \%)$ atuam como docentes há mais de 10 anos, o que revela que a maioria tem experiência profissional. Das entrevistadas, doze $(85,7 \%)$ trabalham exclusivamente no Ensino Fundamental, uma $(7,1 \%)$ no Ensino Fundamental e na Educação Infantil e uma (7,1\%) no Ensino Fundamental e no Ensino Superior. Em relação ao número de turmas, onze $(78,6 \%)$ professoras trabalham exclusivamente com uma turma e três $(21,4 \%)$ trabalham com duas turmas. Sete professoras $(50 \%)$ enfrentam uma jornada de trabalho de 40 horas semanais, seis $(42,9 \%)$ trabalham 20 horas e apenas uma $(7,1 \%)$ trabalha até 10 horas. Do total de entrevistadas, dez $(71,4 \%)$ exercem somente a docência e quatro $(28,6 \%)$ atuam também em outras atividades (Pedagoga e Tutora de Educação a Distância). Por fim, treze $(92,9 \%)$ professoras realizaram curso de aperfeiçoamento nos últimos dois anos, ainda que sejam, em grande parte, apenas os oferecidos pela Secretaria Municipal de Educação (SEDUC). Apenas uma $(7,1 \%)$ professora não realizou curso de aperfeiçoamento. A idade média das professoras entrevistadas é de 38 anos.

No que se refere ao número de observações em sala, este foi definido pela direção de cada escola. Para a análise das observações selecionamos as que puderam ser realizadas com a presença da professora regente em sala de aula, em um dia com atividades rotineiras. Sendo assim, descartamos os casos em que a professora substituta assumiu a sala devido à ausência da professora regente ou os casos em que a turma estava em avaliação e atividades extracurriculares (Educação Física, Artes, etc.). É importante ressaltar que em cada sala foi realizada uma observação de 4 horas, perfazendo um total de 10 observações. Cada turma contava com aproximadamente 20 alunos, dentre os quais estavam os que possuem diagnóstico de TDAH. Apenas duas professoras não autorizaram a observação em sala.

Com a análise das observações pudemos constatar que, do total de 153 alunos nas 10 turmas observadas e analisadas, $6 \%\left(\mathrm{n}^{\mathrm{o}} 10\right)$ possuem diagnóstico de TDAH, sendo sete meninos e três meninas. De acordo com Benczik (2010), a prevalência de crianças com TDAH em literaturas internacionais é de 3\% a $6 \%$ em crianças em idade escolar; essa porcentagem é aceita pela Organização Mundial de Saúde (OMS), que acredita que a manifestação desse transtorno em crianças escolares é mínima, não sendo coerente com os altos números de diagnósticos que alguns países, como o Brasil, divulgam. A porcentagem de crianças observadas e analisadas com o diagnóstico pode ser um indicativo de um possível equívoco nos diagnósticos, visto que a 
amostra é pequena e há muitas outras crianças matriculadas que também são diagnosticadas com TDAH e não foram observadas nesta pesquisa.

Outro fato que as observações mostraram é que as professoras não se incomodaram com a presença da pesquisadora em sala de aula, pois a viram como uma ajuda para lidarem com o transtorno. Muitas manifestaram que não concordam com o diagnóstico, pois as características não são as mesmas que ouvem em cursos ou lêem em livros, como hiperatividade e impulsividade, mas não relataram se fazem algo para mudar esse quadro, ou se relacionam o comportamento de seus alunos diagnosticados com TDAH aos efeitos dos medicamentos, bem como se este pode influenciar o desenvolvimento motor (comportamento) dos usuários.

Segundo Vianna (2007), é comum vermos em relatos de observação em pesquisas semelhantes que o professor não ficou satisfeito com a presença do pesquisador, pois isso pode causar, além de seu desconforto, a fuga de domínio sobre a turma, que possivelmente fica mais agitada. É inquestionável a ruptura no cotidiano da sala causada por essa presença, porém, em nosso caso, as professoras a viram como um meio de finalmente serem ouvidas, uma chance de manifestarem suas opiniões sobre seus alunos diagnosticados, com base na prática pedagógica, nas dificuldades escolares e outros aspectos cognitivos. As docentes também questionaram sobre pesquisas recentes sobre TDAH, as formas de tratamentos e outros aspectos, sobretudo voltados às etapas de diagnósticos do referido transtorno.

As observações no quesito comportamental dos alunos com diagnóstico de TDAH não apontaram nenhuma característica de hiperatividade e/ou impulsividade. Algumas professoras relataram que seus alunos são muitos "tranquilos". Em relação ao processo de ensino e de aprendizagem, notamos que praticamente todos os alunos realizaram as atividades propostas. A relação entre professoras e alunos, em geral, é boa, assim como a das demais crianças com os alunos que possuem diagnóstico de TDAH.

$\mathrm{Na}$ literatura científica vemos com frequência indícios do comportamento do aluno com TDAH descrito como indisciplina, alguns estudos até se propõem a esclarecer a diferença entre o transtorno e a indisciplina (ZORZAN, 2010; COSTA, 2010), porém, os resultados de nossas observações vão de encontro com essas afirmações, pois além de as professoras relatarem comportamentos comuns a quaisquer crianças (com ou sem TDAH), verificamos que se não nos fossem apontados os alunos diagnosticados, mal poderíamos identificá-los pelos comportamentos.

De modo geral, o que podemos considerar das observações dos alunos com diagnóstico de TDAH e os aspectos relacionados a eles (comportamento, aprendizagem e relacionamento 
interpessoal) é que tais alunos se assemelham aos demais, em grande parte. Com relação ao comportamento, nenhum aluno com o diagnóstico apresentou hiperatividade e/ou impulsividade. A atenção dos alunos é algo difícil de constatar, mas, pelo fato de conseguirem realizar as atividades propostas, acreditamos que estavam atentos às explicações e comandos de suas professoras.

Ao contrapormos com as características apresentada pelo Manual Diagnóstico e Estatístico de Transtornos Mentais (DSM) que está em sua quinta edição, verificamos que as características mais marcantes descritas como as que definem o sujeito com TDAH não foram observadas e vão contra a definição de "tranquilo", a qual as professoras utilizaram. Segundo o DSM-V (2014, p. 101):

A hiperatividade refere-se a atividade motora excessiva (como uma criança que corre por tudo) quando não apropriado ou remexer, batucar ou conversar em excesso [...]. A Impulsividade refere-se a ações precipitadas que ocorrem no momento sem premeditação e com elevado potencial para dano à pessoa ( $\mathrm{p}$. ex., atravessar uma rua sem olhar).

Ainda de acordo o DSM-V (2014), isso deve ser considerado um indicativo de transtorno quando ocorre em demasia, ou seja, com maior frequência e intensidade do que em demais crianças. Considerando o correr e outras ações infantis como parte de uma brincadeira, bem como nas palavras de Vygotsky (1991), que caracteriza o brincar como parte do comportamento infantil, necessário para o desenvolvimento cognitivo, não observamos nenhuma atividade motora excessiva e nem que tivesse elevado potencial de dano a qualquer aluno. Assim, todas as atitudes observadas dos alunos com diagnóstico de TDAH são comuns em qualquer criança.

Ao questionarmos as professoras sobre quais alunos observados utilizam medicamentos como forma de tratamento, obtivemos um total de $82 \%$. Veja mais informações no gráfico a seguir:

Gráfico 1: Formas de tratamento e medicamentos utilizados para TDAH em uma amostra de escolas públicas de uma cidade do interior do Paraná 


\section{Formas de tratamentos para TDAH}

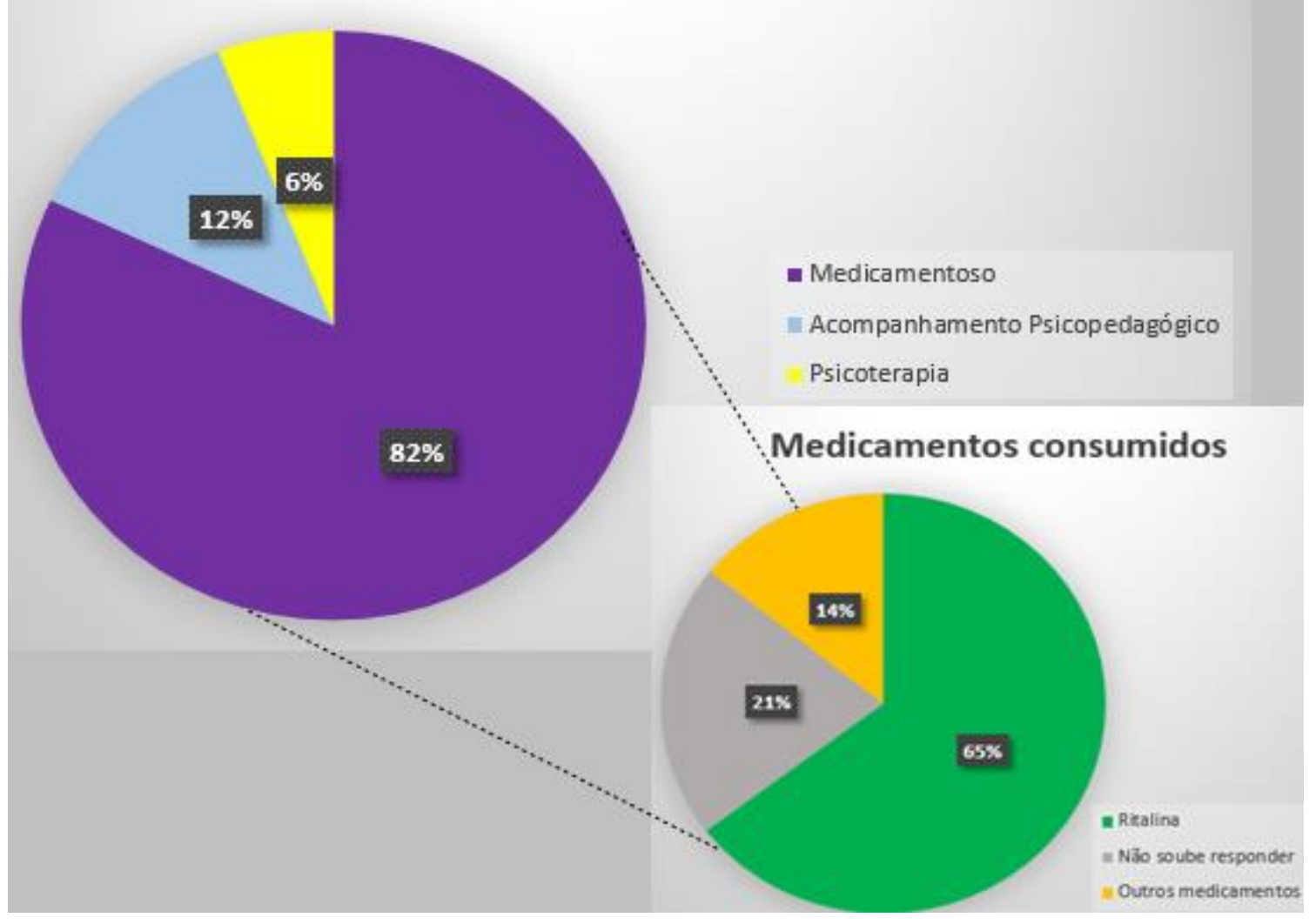

Fonte: Cordeiro (2016)

Do percentual de crianças medicalizadas, descobrimos que $65 \%$ utilizam Ritalina ${ }$, sem contar os $21 \%$ que as professoras não souberam informar qual medicamento seus alunos estavam fazendo uso. Nesse ínterim, pelo que as pesquisas sobre medicalização afirmam a favor dos medicamentos no tratamento de TDAH, deveríamos ver uma diferença entre as crianças que os utilizam das que não utilizam (18\%), no entanto, conforme já mencionado, o comportamento das crianças com o diagnóstico de TDAH não destoava em relação aos demais alunos da sala e nem entre si.

A única dificuldade encontrada nas realizações das atividades foi em relação à organização de espaço. Os demais não apresentaram dificuldades. Houve, apenas, um caso em que um aluno não quis realizar as atividades e outro que apresentou cansaço no fim do período de aula. De acordo com Benczik (2010), faz parte da característica do TDAH a falta de organização de seus pertences, assim, no caso das crianças, seria comum vermos a carteira desorganizada; bolsa no chão; papéis, cadernos e outros objetos em cima da mesa de forma aleatória; no entanto, não observamos esse cenário na maioria dos alunos. 
Essas observações foram contrapostas com o Teste de Associação Livre de Palavras (TALP), aplicado às professoras observadas. Para realizar as análises do TALP, classificamos as respostas das entrevistadas em seis categorias de análise: a) conceito de TDAH; b) definição de crianças com TDAH; c) relação professor-aluno; d) práticas pedagógicas que não utilizaria; e) práticas pedagógicas que utilizaria; e f) formas de tratamento.

Veja no quadro a seguir a tabulação das evocações das professoras sobre o TDAH e os aspectos relacionados ao transtorno, dentre eles, a medicalização como forma de tratamento:

Quadro 1: Representações sociais de professores por meio do Teste de Associação Livre de Palavras

\begin{tabular}{|c|c|c|}
\hline Categoria analítica & Conteúdo das representações & $\begin{array}{c}\text { Frequência } \\
\text { (professoras) }\end{array}$ \\
\hline \multirow{8}{*}{ Conceito de TDAH } & Transtorno/dificuldade que afeta a aprendizagem & 4 \\
\hline & Falta de atenção & 3 \\
\hline & Difícil de administrar & 2 \\
\hline & Transtorno na sala & 1 \\
\hline & Desafio & 1 \\
\hline & Falta de concentração & 1 \\
\hline & Agitação & 1 \\
\hline & Não é algo verdadeiro & 1 \\
\hline \multirow{5}{*}{$\begin{array}{l}\text { Definição de crianças } \\
\text { com TDAH }\end{array}$} & $\begin{array}{l}\text { Definição com base em comportamentos (agitadas, muito } \\
\text { agitadas, hiperativas) }\end{array}$ & 6 \\
\hline & Difíceis & 4 \\
\hline & Qualidades positivas (maravilhosas, muito inteligentes) & 2 \\
\hline & Dependentes & 1 \\
\hline & Vítimas de um sistema & 1 \\
\hline \multirow{6}{*}{$\begin{array}{l}\text { Relação professor- } \\
\text { aluno }\end{array}$} & Tranquilo/comum/normal & 5 \\
\hline & Complicado/dificultoso & 5 \\
\hline & Com paciência e interesse & 1 \\
\hline & Razoável & 1 \\
\hline & Intenso & 1 \\
\hline & Bom & 1 \\
\hline \multirow{4}{*}{$\begin{array}{l}\text { Práticas pedagógicas } \\
\text { que não realizaria }\end{array}$} & $\begin{array}{l}\text { Que exijam concentração (produção textual/leitura } \\
\text { prolongada/atividades grandes) }\end{array}$ & 8 \\
\hline & Que exijam movimentos (agitação/corrida/passeios) & 4 \\
\hline & Realizaria todas & 1 \\
\hline & Não soube r esponder & 1 \\
\hline \multirow{8}{*}{$\begin{array}{l}\text { Práticas pedagógicas } \\
\text { que realizaria }\end{array}$} & Atividades lúdicas (jogos/brincadeiras/de interação) & 6 \\
\hline & Individualizadas & 2 \\
\hline & Curtas & 1 \\
\hline & Diversificadas & 1 \\
\hline & Que exijam raciocínio lógico e que chamem atenção & 1 \\
\hline & Que exijam atenção e concentração & 1 \\
\hline & Normais 3 & 1 \\
\hline & Todas & 1 \\
\hline \multirow{4}{*}{ Formas de tratamento } & Medicamento & 6 \\
\hline & $\begin{array}{l}\text { Medicamento e outros tratamentos dependendo do caso formas } \\
\text { (Psicoterapia, acompanhamento psicopedagógico, etc.) }\end{array}$ & 6 \\
\hline & Medicamento e Psicoterapia & 1 \\
\hline & Acompanhamento psicopedagógico & 1 \\
\hline
\end{tabular}

Fonte: Cordeiro (2016). 
A categoria "conceito de TDAH" corresponde à resposta da seguinte pergunta indutora feita às docentes: “O TDAH é...?”. Tínhamos como hipótese que a maioria das respostas seria "uma doença", partindo do que alguns meios midiáticos apresentam com pseudociências. No entanto, podemos observar no quadro acima que o termo "transtorno" é o que mais aparece nas representações das professoras em relação ao TDAH e é relacionado ao campo da Educação, pois de acordo com a fala de algumas docentes, esse transtorno, ou dificuldade, influencia na aprendizagem. Três professoras utilizaram o termo "falta de atenção" e duas o termo "difícil de administrar".

Segundo Moscovici (2015), as representações sociais podem ser identificadas pelo processo de ancoragem, ou seja, significados atribuídos ao objeto (no caso o TDAH) que estão relacionados a valores e práticas sociais, tais como vimos com o grupo que significou o TDAH a partir de uma representação ligada à dificuldade de aprendizagem, construída a partir de sua prática social.

Essa visão sobre o TDAH com um olhar mais pedagógico é de extrema importância para o aluno, que é beneficiado com os esforços do professor para ajudá-lo a alcançar a aprendizagem de direito. Quando o docente percebe que o transtorno oferece implicações na aprendizagem do aluno, compreende que é a equipe pedagógica como um todo que deve auxiliá-lo, visto que a dificuldade na aprendizagem escolar é de responsabilidade do professor e, sendo assim, é ele quem deve saná-la.

$\mathrm{Na}$ categoria "definição de criança com TDAH" a pergunta indutora foi "As crianças com TDAH são...?". Notamos que as respostas que se repetiram com maior frequência foram: "agitadas", "muito agitadas" e "hiperativas". Quatro professoras definiram como "difíceis". Duas apresentaram características positivas: "maravilhosas" e "muito inteligentes". Essas evocações com maior repetição estão relacionadas ao comportamento e não ao desempenho escolar, contudo, vão de encontro com os relatos durante as observações, em que a maioria definiu seu aluno como "tranquilo". Há um conflito de ideias entre o que as professoras definem e o que de fato elas possuem em sala de aula, eis o motivo de a maioria ter mencionado que não concordam com alguns diagnósticos. De fato, as características descritas na literatura científica e a evocação das professoras não estão em comum acordo com o que elas veem no cotidiano escolar.

Este fato se explica, provavelmente, na organização das representações sociais, uma vez que estas não significam apenas reproduções da realidade, mas pertencem a um contexto mais imediato e a outro, mais global. No caso das professoras participantes da presente pesquisa, o mais imediato seria a realidade da escola e de suas práticas pedagógicas em sala de aula, das 
trocas entre os seus pares, dos cursos de formação continuada e das interações com os alunos e pais. O contexto global, por sua vez, seria a concepção do transtorno pesquisado, sob o viés clínico, portanto, de cunho eminentemente científico, que nem sempre se encontra representado nas concepções sobre uma dada realidade, ainda que esta seja uma instituição escolar que veicula conhecimentos reificados.

A categoria "relação professor-aluno" teve como pergunta indutora: "Meu relacionamento com o aluno TDAH é...?", em que cinco professoras consideraram como: "tranquilo", "comum" e "normal". Por outro lado, outras cinco definiram sua relação com o aluno com TDAH como: "complicado" e "dificultoso". O relacionamento entre professor-aluno não acontece da mesma forma e na mesma proporção com todas as crianças, pois cada uma tem seu próprio jeito, possibilitando ou não a aproximação do professor de diferentes formas. Esse entendimento é melhor explicado por Deschamps e Moliner (2014, p. 139), ao afirmarem que “[...] indivíduos que têm uma mesma representação (organizada em torno de um mesmo núcleo) terão às vezes práticas sensivelmente diferentes". E essas diferenças são acentuadas ou minimizadas pelas características individuais dos sujeitos e pelas circunstâncias de uma dada situação interlocutiva.

$\mathrm{Na}$ categoria "práticas pedagógicas que não realizaria" a pergunta indutora foi "Uma atividade que não realizaria com aluno TDAH é...?”. Podemos notar que as atividades que "exigem concentração" e envolvem um tempo prolongado são aquelas que não seriam utilizadas pela maior parte das professoras. Quatro professoras evitariam atividades que "exigissem movimentos" (corrida, passeios, etc.).

É importante salientar que a atenção e a praxia (controle dos movimentos) são funções psicológicas superiores capazes de serem desenvolvidas. Na criança com TDAH esses elementos precisam de mais estímulos do que nas demais, para que ele possa desenvolver a atenção e o controle dos impulsos, ainda que biologicamente tenha-se um dano neurológico (LURIA, 1981).

Em relação à categoria "práticas pedagógicas que realizaria", tivemos como pergunta indutora: "Uma atividade que realizaria com aluno TDAH é...?". A resposta que ocorreu com maior frequência foi "utilização de atividades lúdicas", o que está de acordo com o que propõe Benczik (2010). Os métodos mais utilizados na Psicopedagogia, por exemplo, são os jogos de exercícios sensório-motor (amarelinha, brincadeiras com bola, dentre outros que envolvam o corpo) e os jogos que tenham combinações intelectuais (xadrez, quebra-cabeça, jogo da memória, dentre outros que envolvam percepção e raciocínio lógico, por exemplo). 
De acordo com Benczik (2010), esses jogos com regras permitem o desenvolvimento de aspectos sociais e cognitivos, além de propiciar a criança a ver seus erros, os motivos que a levaram a errar e a forma de não cometê-los novamente, dentre outros aspectos. Em sala de aula os jogos podem ser utilizados como materiais de mediação do conteúdo e permitem trabalhar com as dificuldades específicas de aprendizagem dos alunos, ajudando-os na apreensão dos conteúdos escolares.

Um fato interessante ocorreu na última categoria analisada (formas de tratamento), cuja pergunta indutora foi “A melhor forma de tratamento para TDAH é...?”. Ao realizarmos o TALP, esperávamos que as professoras respondessem que a melhor forma de tratamento fosse alguma vista na literatura que lhes viesse à mente, no entanto, a primeira resposta que a maioria mencionou referia-se à relação entre professor-aluno, aparecendo as palavras: "paciência/muita paciência", "compreensão", "conversa", "temperança” e "igualdade”. Após expressarem essas representações como a melhor forma de tratamento para o TDAH, perguntamos sobre a melhor forma de tratamento extraescolar para esses casos.

Notamos que praticamente todas as docentes participantes da pesquisa veem o medicamento como a melhor forma de tratamento, visto que apenas uma citou uma forma diferente. Seis das 14 professoras entrevistadas responderam exclusivamente o medicamento. Outras seis consideram que deve haver a associação de medicamentos com outros tipos de tratamento, dependendo do caso. Uma considera viável o tratamento com "medicamento e psicoterapia" e uma aponta apenas o "acompanhamento psicopedagógico".

Esta concepção abarcada pelo conhecimento consensual de que a medicalização seria a forma mais eficaz de tratamento extraescolar, incidida, pela ação prolongada do princípio ativo do medicamento, no processo de aprendizagem em sala de aula. Assim sendo, conhecimentos reificados não são necessários para a compreensão de representações, o que, segundo Moscovici (2015, p. 52), estas “[...] restauram a consciência coletiva e lhes dão forma, explicando os objetos e acontecimentos de tal modo que eles se tornam mais acessíveis a qualquer um e coincidem com nossos interesses imediatos". Interesses muitas vezes equivocados, e que, via de regra, corroboram com o entendimento de que o aluno com TDAH medicado preste mais atenção às aulas e mantenha o foco na aprendizagem, ao passo que o professor "consiga" conduzir suas aulas e dar conta das demandas docentes.

$\mathrm{Na}$ interpretação de Machado e Silva (2014), as representações sociais tornam reais os conceitos, modos de entender o mundo que criamos em nossa rotina diária. São associações que as pessoas fazem quando surgem determinados "assuntos sociais", os quais exigem uma resposta 
que esteja baseada no conhecimento adquirido nos processos de experiências acumuladas pelos indivíduos. Nas falas das professoras podemos identificar os significados atribuídos ao TDAH e à própria criança que recebe o diagnóstico. De acordo com Jodelet (2017), o fato de o sujeito estar em um determinado grupo social possibilita que ele formule conhecimentos coletivos, dessa forma, esses conhecimentos apresentados pelos professores foram construídos socialmente e traduzem o TDAH como um transtorno com implicações na aprendizagem, no qual a criança mostra-se agitada e desatenta e seu tratamento depende predominantemente do medicamento, ainda que outras formas sejam utilizadas.

Podemos inferir que essas representações sociais das professoras estão ancoradas em “conceitos científicos" e "pseudocientíficos" propagados pela mídia, pelos cursos de formação de professores e pela orientação dada às escolas pelos profissionais da Saúde. Embora as professoras em certos momentos manifestem dúvida em relação ao diagnóstico recebido pelos alunos, parecem concordar com o processo de medicalização do TDAH. Estes dados indicam a necessidade de políticas públicas para a Educação, principalmente nos cursos de formação de professores e em particular os de formação continuada, sejam direcionados à desmistificação dos estereótipos referentes à "medicalização do ensino", ou seja, que as reflexões sobre esta temática levem os profissionais da Educação a se instrumentalizarem em seu trabalho pedagógico, com estratégias e práticas de ensino e de aprendizagem condizentes com as necessidades especiais dos estudantes com TDAH.

\section{Considerações finais}

A prática pedagógica é uma questão essencial nas discussões sobre educação escolar, especialmente devido ao seu importante papel na mudança ou manutenção de determinado modo de organização do sistema educacional. Por isso, as representações que esses professores têm, consciente ou inconscientemente, sobre os conceitos de TDAH e de medicalização, influenciam sobremaneira na forma como o professor conduzirá seu trabalho pedagógico. Assim, se o professor atribui somente à criança o problema da falta de atenção e não se vê como elemento de autoridade no processo de aprendizagem e desenvolvimento, pode ser algo preocupante, uma vez que encaminhar a criança para especialistas e solicitar a medicalização dos problemas de atenção e impulsividade acaba sendo a saída encontrada para tratar questões que são de ordem pedagógica. 
A Teoria das Representações Sociais foi de fundamental importância para identificarmos os conhecimentos socialmente elaborados pelo grupo de professoras. Constatamos, por meio da pesquisa, ao juntarmos os dados das observações e do Teste de Associação Livre de Palavras, que a representação da maioria das professoras acerca do TDAH é que ele se caracteriza como um transtorno que afeta a aprendizagem. Tal representação social, elaborada no meio escolar, se difere dos conceitos mais apresentados pela literatura, em que imperam os clínicos, por exemplo, as características (desatenção, hiperatividade e impulsividade), bem como o termo "doença" para designar o TDAH.

Esse resultado é considerado importante para a área da Educação, pois revela que as professoras entendem que o problema maior do TDAH está na dificuldade escolar que o aluno apresenta. Sendo assim, a maior contribuição do professor consiste em ajudar o aluno a superar essas dificuldades e potencializar suas habilidades, transmitindo o conhecimento científico e formando o sujeito para a sociedade, visto que esse é o papel dos educadores.

Em outras palavras, conceber o TDAH como um transtorno neurobiológico com repercussões no processo de aprendizagem implica assumir a responsabilidade de educar e não deixar apenas para os médicos, os psicólogos, os psicopedagogos, etc., a responsabilidade do caso. No entanto, nas representações sociais dos professores acerca do tratamento do TDAH, a forma de tratamento vista como a mais indicada ainda é a medicação; fica, então, uma reflexão aos professores: se o TDAH é um transtorno que afeta a aprendizagem, por que a ênfase no tratamento recai no uso do medicamento? Não seria melhor investir em práticas pedagógicas que favorecessem o processo de ensino e de aprendizagem do aluno com TDAH?

Acreditamos que intervenções pedagógicas apropriadas são de suma importância para as crianças com TDAH. O comportamento e outros aspectos relacionados às características desse transtorno podem ser trabalhados com psicoterapia e outros tratamentos que não necessariamente utilizem o medicamento, que pode causar efeitos colaterais indesejáveis no sujeito. Esperamos que essa pesquisa agregue contribuições para a reflexão dos professores acerca de suas responsabilidades no ambiente escolar com a criança com diagnóstico de TDAH. Desejamos que os docentes, ao lerem o presente trabalho, repensem nas práticas pedagógicas como tratamentos pedagógicos para os alunos com o referido transtorno, uma vez que a escola é o espaço mais adequado para que diferentes formas de intervenções aconteçam.

Não queremos atribuir à escola mais um trabalho, nem isentar os clínicos de suas responsabilidades, mas mostrar ao professor que ele também tem autonomia sobre esse delicado problema. $\mathrm{O}$ docente pode e deve contribuir para a diminuição de diagnósticos equivocados, para 
a melhor qualidade de vida do aluno com TDAH e para a aprendizagem dessas crianças que se encontram em tratamento. Uma das maneiras possíveis de ajudar é expressando em seus relatórios essa visão de que muitos "sintomas" não estão presentes nessas crianças. Além disso, muitas características consideradas específicas do TDAH podem estar articuladas a uma determinada situação, por exemplo, aulas sem ludicidades, o que gera desinteresse por parte dos alunos e, por consequência, agitação. Também é importante que os profissionais da área da Saúde ajudem a escola e a família com os casos de TDAH, realizando um trabalho interdisciplinar em prol da qualidade de vida.

Entendemos que, cada vez mais, a escola tem assumido papéis que antes eram atribuídos à família. Todavia, seu papel principal é educar com base em conhecimentos científicos em uma perspectiva democrática e assegurar que todos os seus alunos tenham uma educação escolar de qualidade, incluindo as crianças que de fato têm TDAH. Para tanto, o professor deve conhecer cada vez mais o seu aluno e a sociedade em que está, sendo necessário pesquisar sempre e produzir pesquisas, o que também ajudará a sociedade a compreender o interior da escola e as práticas pedagógicas que nela acontecem.

As reflexões tecidas neste estudo nos levam a afirmar que é de suma importância que a prática indiscriminada de encaminhamentos seja repensada. Nesse sentido, concordamos com Bray e Leonardo (2011) ao afirmarem que, muitas vezes, os diagnósticos "revelam" a presença de deficiências ou distúrbios nos alunos encaminhados, qualificando-os como portadores de desequilíbrios, deficiências, distúrbios emocionais ou neurológicos, agressividade, hiperatividade, apatia, e conferindo-lhes muitas outras rotulações. Assim, os problemas escolares permanecem individualizados, isto é, no aluno, com o estereótipo de que ele não tem capacidade para aprender, enquanto as dimensões sociais e políticas da sociedade capitalista continuam não merecendo consideração, principalmente por parte da instituição escolar. Em outras palavras, todos devem lutar para que os diagnósticos equivocados deixem de ser uma prática tão comum com repercussões terríveis para crianças e adolescentes.

AGRADECIMENTOS: Nossos agradecimentos aos professores que colaboraram com essa pesquisa e à SEDUC da cidade na qual desenvolvemos o estudo, pelo fato de nos ceder os espaços para as observações e entrevistas.

\section{REFERÊNCIAS}

ALVES-MAZZOTTI, A. J. Representações Sociais: Aspectos Teóricos e Aplicações à Educação.Revista Múltiplas Leituras, São Paulo, v.1, n. 1, p. 18-43, jan./jun. 2008. Disponível 
em: <https://www.metodista.br/revistas/revistas-ims/index.php/ML/article/view

File/1169/1181>. Acesso em: 19 set. 2017.

BENCZIK, E. B. P. Transtorno de Déficit de Atenção/Hiperatividade: Atualizações

Diagnósticas e Terapêuticas: Um Guia de Orientação para Profissionais. São Paulo: Casa do

Psicólogo, 2010.

BRAY, C. T.; LEONARDO, N. S. T. As Queixas Escolares na Compreensão de Educadoras de Escolas Públicas e Privadas. Revista Semestral da Associação Brasileira de Psicologia Escolar e Educacional, Maringá, v. 15, n. 2, p. 251-261, dez. 2011.

CORDEIRO, S. M. N. As representações sociais de professores do Ensino Fundamental sobre TDAH e medicalização. 2016. 133 f. Dissertação (Mestrado em Educação) Universidade Estadual de Maringá, Maringá, 2016.

COSTA, S. A. S. Um desafio de inclusão para professores: Aluno com Transtorno de Déficit de Atenção/Hiperatividade. 2010. 52 f. Trabalho de Conclusão de Curso (Graduação em Pedagogia) - Universidade Federal do Rio Grande do Sul, Porto Alegre, 2010.

CRUZ, M. G. A.; OKAMOTO, M. Y.; FERRAZZA, D. A. O caso Transtorno do Déficit de Atenção e Hiperatividade (TDAH) e a medicalização da educação: Uma análise a partir do relato de pais e professores. Interface, Botucatu, v. 20, n. 58, p. 703-714, 2016. Disponível em: <http://www.scielo.br/pdf/icse/v20n58/1807-5762-icse-1807-576220150575.pdf〉. Acesso em: 22 set. 2017.

CRUZ, B. A.; LEMOS, F. C. S.; PIANI, P. P. F.; BRIGAGÃO, J. I. M. Uma crítica à produção do TDAH e a administração de drogas para crianças. Estudos de Psicologia, Natal, v. 21, n. 3, p. 282-292, jul./set. 2016. Disponível em: 〈http://www.redalyc.org/pdf/261/26149979006.pdf>. Acesso: 21 out. 2017.

DESCHAMPS, J. C.; MOLINER, P. A identidade em psicologia social: dos processos indenitários às representações sociais. Petrópolis, RJ: Vozes, 2014.

ASSOCIAÇÃO DE PSIQUIATRIA AMERICANA (APA). Manual Diagnóstico e Estatístico de Transtornos Mentais (DSM-V). 5. ed. Tradução de Maria Inês Correa Nascimento et al. Porto Alegre: Artmed, 2014.

JODELET, D. Representações sociais e mundos de vida. São Paulo: Fundação Carlos Chagas, 2017.

LEONARDO, N. S. T.; SUZUKI, M. A. Medicalização dos problemas de comportamento na escola: Perspectivas de professores. Fractal: Revista de Psicologia, v. 28, n. 1, p. 46-54, jan./abr. 2016. Disponível em:

<http://www.periodicoshumanas.uff.br/Fractal/article/viewFile/1161/1266>. Acesso em: 12 dez. 2017.

LURIA, A. R. Fundamentos de Neuropsicologia. Rio de Janeiro: Livros Técnicos e Científicos; São Paulo: Editora da Universidade de São Paulo, 1981. 
MACHADO, L. B.; SILVA, W. F. S. Implicações das Representações Sociais de Ciclos de Aprendizagem nas Práticas Professoras de Sucesso. Revista Cocar, Belém, v. 8, n. 15, p. 88-96, jan./jul. 2014. Disponível em:

<http://paginas.uepa.br/seer/index.php/cocar/article/viewFile/339/316>. Acesso em: 30 set. 2017.

MOSCOVICI, S. Representações sociais: Investigações em psicologia social. 11. ed.

Petrópolis: Vozes, 2015.

VIANNA, H. M. Pesquisa em Educação: A observação. Brasília, DF: Liber Livro, 2007.

VYGOTSKY, L. S. Aprendizagem e desenvolvimento intelectual na Idade Escolar. In:

VYGOTSKY, L. S.; LURIA, A. R.; LEONTIEV, A. N. A formação social da mente. 4. ed.

São Paulo: Martins Fontes Editora Ltda, 1991.

ZORZAN, R. T. T. Hiperatividade: Um olhar psicopedagógico. REI, Getúlio Vargas, v. 5, n. 10, jan./jun. 2010. Disponível em:

<http://www.ideau.com.br/getulio/restrito/upload/revistasartigos/204_1.pdf >. Acesso em: 3 out. 2017.

\section{Como referenciar este artigo}

CORDEIRO, Suzi Maria Nunes; YAEGASHI, Solange Franci Raimundo; OLIVEIRA, Lucilia Vernaschi de; COUTINHO, Karen de Azevedo; RUIZ, Nathália Fafarão. Representações sociais sobre TDAH e medicalização. Revista Ibero-Americana de Estudos em Educação, Araraquara, v. 13, n. 03, p. 1011-1027, jul./set., 2018. E-ISSN: 1982-5587. DOI: 10.21723/riaee.v13.n3.2018.10883

Submetido em: 11/01/2018

Revisões requeridas: $05 / 03 / 2018$

Aprovado em: 16/05/2018 